\title{
Reflexiones metodológicas en torno a la Semántica: el caso de la ambigüedad y la sinonimia ${ }^{1}$
}

\author{
Andrea Ariño-Bizarro²; Natalia López-Cortés ${ }^{3}$
}

Recibido: 29 de julio de 2020 / Aceptado: 19 de abril de 2021

Resumen. La Semántica sigue siendo una disciplina que queda en un segundo plano en la clase de Lengua y Literatura. En algunos libros de texto, se establecen ejercicios sistemáticos que tienden a la repetición de las definiciones y dejan a un lado el aprendizaje significativo del alumnado. Sin embargo, los fenómenos semánticos son una oportunidad perfecta para convertir a los alumnos en los protagonistas de la reflexión metalingüística. En este trabajo se presenta una reflexión sobre dos de los fenómenos semánticos estudiados a lo largo de toda la Educación Secundaria Obligatoria: la ambigüedad léxica y la sinonimia. El objetivo que se persigue es doble: por un lado, actualizar la base teórica relativa a estos fenómenos y, por otro lado, mostrar cómo es posible enriquecer los materiales y actividades de los que disponemos en el aula. De esta manera, se establecen pautas para la mejora del estudio del significado.

Palabras clave: Semántica; significado; ambigüedad léxica; sinonimia; libros de texto; reflexión metalingüística.

\section{[en] Methodological Considerations on Semantics: The Case of Ambiguity and Synonymy}

Abstract. Semantics is still a field that is normally upstaged in the classroom. Repetitive exercises, that leave no room for significant learning, can be found in many textbooks. However, semantic phenomena represent the perfect opportunity for the students to be at the fore and to activate their metalinguistic abilities. In this paper a reflection on two semantic phenomena is presented: lexical ambiguity and synonymy. The aim of this paper is double: on the one hand, to update the theoretical background regarding these phenomena; on the other hand, to show how to enrichen the materials and activities that are already available in the classrooms. By doing so, guidelines to improve the study of meaning will be established.

Keywords: Semantics; meaning; lexical ambiguity; synonymy; textbooks; metalinguistic reflection.

\section{[fr] Réflexions méthodologiques sur la sémantique: le cas de l'ambiguïté et de la synonymie}

Résumé. La sémantique est une discipline qui demeure reléguée au second plan dans les cours d'espagnol. On trouve dans certains manuels des exercices qui consistent en la répétition systématique de définitions - freinant l'apprentissage significatif des élèves. Les phénomènes sémantiques sont en effet l'occasion pour les élèves de se placer au centre de la réflexion métalinguistique. Leur analyse permet une réflexion autour de deux phénomènes sémantiques travaillés au cours de la ESO (Educación Secundaria Obligatoria): l'ambiguïté lexicale et la synonymie. L'objectif poursuivi est donc double: d'un côté, actualiser de la base théorique relative à ces phénomènes, et de l'autre, montrer la possibilité d'enrichissement des matériaux et activités proposés en cours. De cette manière peuvent s'établir des directives pour l'amélioration de l'étude de la signification.

Mots-clés: Sémantique; signification; ambiguïté lexique; synonymie; livres de texte; réflexion métalinguistique.

Sumario: 1. Introducción. 2. Ambigüedad léxica. 2.1. Repaso teórico. 2.2. Repaso de los materiales didácticos 2.3. Reflexiones metodológicas. 3. Sinonimia. 3.1. Repaso teórico. 3.2. Repaso de los materiales didácticos 3.3. Reflexiones metodológicas. 4. Conclusiones 5. Bibliografía

Cómo citar: Ariño-Bizarro, Andrea; López-Cortés, Natalia (2021). Reflexiones metodológicas en torno a la Semántica: el caso de la ambigüedad y la sinonimia. Didáctica. Lengua y Literatura, 33, 83-94.

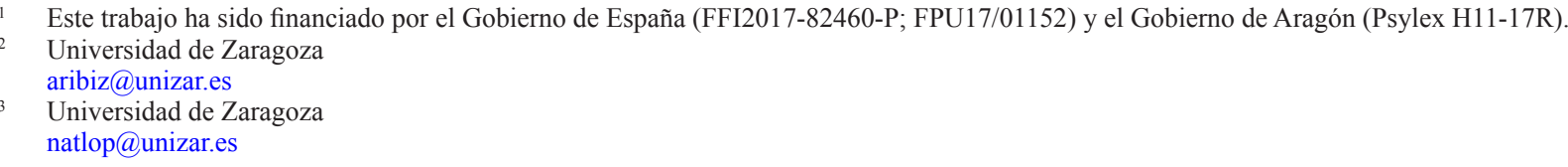




\section{INTRODUCCIÓN}

La Semántica es la disciplina lingüística que estudia el significado que comunicamos mediante el lenguaje natural (López, 2016). Es, por tanto, una parte de la gramática que analiza el modo en el que los hablantes representan el mundo haciendo uso de la lengua. Si el papel de la enseñanza de la lengua es ampliar y consolidar las competencias comunicativas del alumnado (Real Decreto 1105/2014), es de vital importancia que sean conocedores de estas consideraciones sobre el significado. Para ello, es necesaria su revalorización en el aula de Secundaria. Sin embargo, su estudio no debe ser desarrollado como una mera lista de fenómenos, sino que ha de ser presentado como una capacidad intrínseca de la comunicación humana que tenemos desde que nacemos (Ariño-Bizarro y López-Cortés, 2020).

Por esta razón, es imprescindible que los alumnos partan de esta naturaleza innata y que sean conscientes de que ellos, como hablantes nativos de su lengua materna, conocen sus mecanismos antes de llegar a la escuela. Así, solo les quedaría reflexionar sobre su funcionamiento de manera explícita, puesto que implícitamente ya los conocen. Esto consigue que el aprendizaje sea significativo (Ausubel, 1960), puesto que los alumnos asocian la información nueva con la que ya poseen como hablantes nativos; $\mathrm{y}$, al mismo tiempo, adquieren el conocimiento lingüístico de un modo más consciente y activo.

De esta manera, la Semántica se establece como una oportunidad magnífica para que los alumnos sean los protagonistas de esta reflexión a partir de sus intuiciones lingüísticas previas, puesto que el significado es un componente de la lengua fácilmente accesible y, a la vez, un muy buen punto de partida para el estudio lingüístico. ${ }^{4}$ En concreto, para este trabajo se han seleccionado los fenómenos semánticos de la ambigüedad léxica y de la sinonimia.

Su elección como ejes vertebradores de esta propuesta tiene una doble justificación: por un lado, son fenómenos lingüísticos que se trabajan de manera recurrente a lo largo de la Educación Obligatoria. En el Real Decreto 1105/2014, que regula el Currículo Básico de la Educación Secundaria y Bachillerato, se mencionan la ambigüedad léxica y la sinonimia tanto como contenidos del bloque de Conocimiento de la lengua como estándares de aprendizaje evaluables. Se establece que el alumno ha de cumplir los siguientes objetivos: "reconoce y usa sinónimos y antónimos de una palabra explicando su uso concreto" (p. 363) o "aplica los conocimientos gramaticales a la evaluación y mejora de la expresión oral, reconociendo ambigüedades" (p. 366).

Además, en este mismo documento se da mucha importancia a la capacidad de interpretar el significado de las palabras, así como al "conocimiento reflexivo de las relaciones semánticas" (p. 363). En este sentido, es especialmente recurrente el uso del adjetivo "reflexivo", con el que quiere hacerse hincapié en la necesidad de que los alumnos piensen sobre su propio instrumento de pensamiento y comunicación: la lengua. ${ }^{5}$

El segundo motivo por el que se han seleccionado estos fenómenos lingüísticos atiende a su importancia en la disciplina Lingüística. Tal y como se refleja en la figura 1, en ambos fenómenos se establece una relación entre las unidades almacenadas en el lexicón mental y los referentes. Por tanto, en ambas situaciones se produce un proceso de denotación complejo, puesto que la relación no es unívoca, sino que hay un mapeo múltiple entre referentes y representaciones lingüísticas.

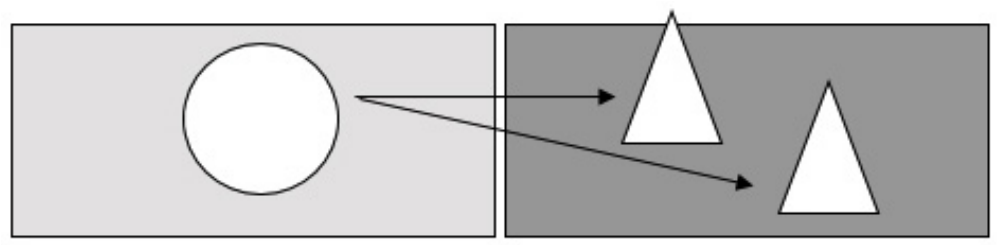

Lexicón Referentes

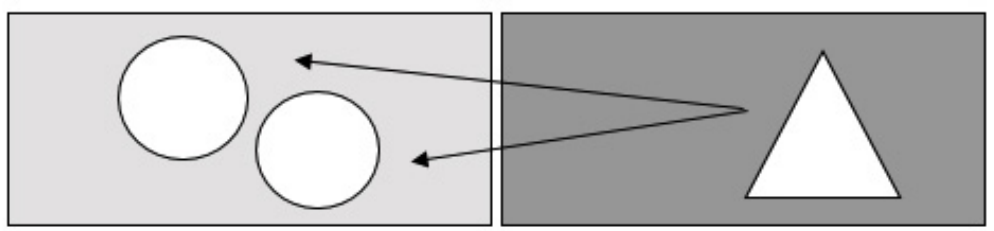

Figura 1. Representación gráfica de la ambigüedad y la sinonimia, respectivamente.

En el caso de la ambigüedad, un único elemento léxico permite nombrar varios elementos de la realidad, mientras que en el fenómeno de la sinonimia se da el proceso contrario: nos referimos a un referente a través de diferentes

4 Para una propuesta más detallada sobre cómo tratar el contenido semántico en clase, se recomienda la lectura de Ibarretxe-Antuñano et al. (en prensa)

5 El estudio de la ambigüedad y de la sinonimia no está restringido a los cursos de Secundaria, sino que ya se comienzan a trabajar en Primaria, como se puede comprobar en el Currículo establecido en el Real Decreto 126/2014. 
posibilidades léxicas, representadas en diferentes regiones de nuestro lexicón. Esta relación entre lengua y constructo mental hace que ambas perspectivas sean interesantes, tanto desde un punto de vista teórico (la definición y delimitación de estos procesos), como desde una perspectiva aplicada (qué coste de procesamiento tienen este tipo de unidades y cómo los hablantes podemos adquirirlas de manera eficaz). Su estudio sigue vigente en la actualidad y, como se verá posteriormente, todavía quedan preguntas sin ser respondidas.

Ambos factores tomados en conjunto (su recurrencia en los planes de estudio y su complejidad lingüística) hacen que se produzcan problemas a la hora de presentar estos fenómenos en los libros de texto. El principal hándicap es que no se delimitan adecuadamente: o bien suelen aparecer listados como elementos independientes o bien se muestran al mismo nivel que otras cuestiones semánticas. Sirva de ejemplo la figura 2, donde aparece la ambigüedad léxica y la sinonimia al mismo nivel que la paronimia y la antonimia.

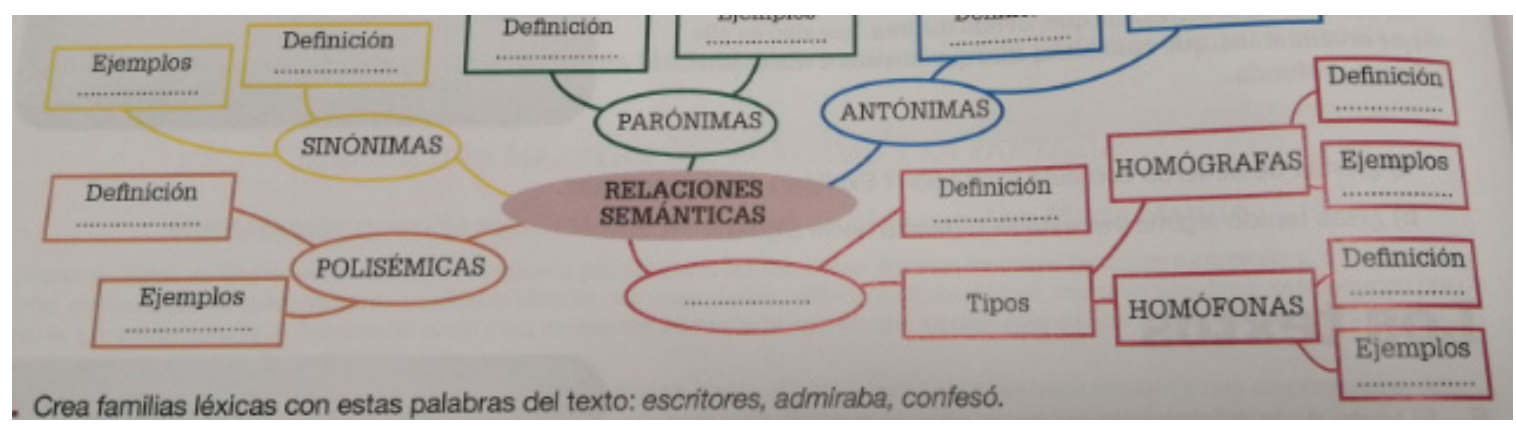

Figura 2. Fuente: SANT3E6

Aunque la relación que existe entre estos elementos lingüísticos es clara (todos se estudian desde la óptica de su significado), no todos suponen el mismo tipo de relación. La pregunta pertinente es, entonces, si la ambigüedad y la sinonimia son verdaderamente el mismo tipo de relación semántica y qué beneficios y desventajas tiene presentarlas como tales en los materiales de clase.

En este trabajo se va a presentar, en primer lugar, una actualización teórica sobre la ambigüedad léxica y la sinonimia para, a continuación, elaborar un repaso crítico de los materiales didácticos que se están utilizando en la actualidad en las aulas con respecto a estos dos fenómenos. Partiendo de todo esto, se proponen sendas reflexiones metodológicas que permitan a los profesores enriquecer los materiales de los que ya disponen para presentar la ambigüedad y la sinonimia de una manera que fomente la reflexión crítica metalingüística.

\section{AMBIGÜEDAD LÉXICA}

\subsection{Repaso teórico}

La ambigüedad léxica se produce cuando una palabra transmite varios significados, como ocurre con lima, que en español puede referirse a una herramienta, a un utensilio, a una fruta o incluso a una acción.

La ambigüedad léxica se opone a lo que tradicionalmente se ha conocido como monosemia y esta oposición nos lleva a varias preguntas que podemos trasladar al aula de Secundaria: ¿existe de verdad la monosemia? y, si es así, ¿qué unidades son monosémicas y por qué?

Para plantear esta idea a nuestros alumnos podemos partir de las palabras recogidas en (1) y pedirles que piensen en sus posibles significados. Tardarán más o menos en recuperarlos, pero pronto se darán cuenta de que todas las palabras, excepto una, pueden significar varias cosas:

1) árbol, mano, cerdo, muñeca, neumonía

La excepción es neumonía: al ser un tecnicismo léxico es una palabra monosémica. Esto hace que se ponga de manifiesto que determinadas unidades léxicas no pueden ser ambiguas porque su contenido semántico es muy específico o técnico.

A todo esto se suma el hecho de que el fenómeno de la ambigüedad no es homogéneo, sino que existen tipos diferentes: la homonimia y la polisemia. ${ }^{7}$ Para definir estos conceptos, existen dos opciones que tienen su base en la oposición clásica de diacronía versus sincronía (Saussure, 1987).

En la bibliografía se recogen todos los manuales consultados. En el texto se han establecido unas abreviaturas para facilitar su citación.

Este trabajo se centra en la ambigüedad léxica, pero existen otros tipos de ambigüedades que también podrían presentarse en el aula. Esto ayudaría a concebir la lengua como un sistema, y no como un mero listado de unidades estancas, sin relación entre sí (Gallego et al., en prensa). 
Así, si partimos de la diacronía, centrándonos en la historia etimológica de las unidades, la homonimia se produce cuando dos palabras con orígenes diferentes coinciden en su representación formal debido a distintos procesos de evolución, como ocurre en el caso de llama, que tiene un origen latino para el significado de 'fuego' y otro quechua, para el de 'animal'. Por otro lado, la polisemia se produce cuando una palabra con un único origen sufre diferentes extensiones de significado con el objetivo de nombrar nuevas realidades o entidades. Esto es lo que ocurre con la palabra pluma, que pasa del significado original 'de ave' para adquirir el de 'estilográfica'.

Desde la aproximación sincrónica, se trata de entender el estatus que las palabras tienen en la actualidad: así, la homonimia y la polisemia se definen en función de las relaciones que se establecen entre sus significados. La homonimia se produce cuando una palabra tiene significados no relacionados (llama-'fuego' y llama-'animal'), mientras que la polisemia se produce cuando los distintos significados de una palabra ambigua están relacionados, porque las extensiones que se han producido son evidentes para los hablantes (pluma-'de ave' y pluma-'estilográfica').

Entonces, ¿qué criterio se ha de elegir para presentar la homonimia y la polisemia en clase? La respuesta dependerá de los objetivos que se quieran perseguir en el aula.

Lo importante es que seamos conscientes de que existen dos criterios diferentes que no tienen por qué ser equivalentes. Tal y como dice Spencer (1991, p. 87), a veces los significados se separan inexorablemente, hasta un punto en el que los hablantes están de acuerdo en que existen dos palabras independientes que se pronuncian igual. Este autor propone el ejemplo de bank, que puede significar tanto 'orilla de un río' como 'institución'. Por su origen etimológico esta palabra es polisémica, pero hoy en día los hablantes, de manera intuitiva, no encuentran relación entre estos dos significados. Así, de una polisemia en la diacronía, se ha pasado a una homonimia en la sincronía. ${ }^{8}$

Por todo ello, es especialmente importante mostrar que cuando estudiamos la ambigüedad léxica tenemos dos oposiciones distintas: por un lado, las palabras con varios significados frente a las palabras con un único significado (ambigüedad-monosemia) y, por otro, la oposición entre los dos tipos de palabras ambiguas (homonimia-polisemia). Pese a que esto pueda parecer obvio, es una de las claves a la hora de estudiar este fenómeno semántico.

Consideramos que, para Secundaria, lo más eficiente es mantener los cuatro términos tradicionales en forma de oposición (monosemia-ambigüedad y homonimia-polisemia). Sin embargo, no todos los manuales respetan esta idea y es por ello por lo que se produce confusión a la hora de delimitar los diferentes fenómenos.

\subsection{Repaso de los materiales didácticos}

En los manuales revisados se han encontrado de manera recurrente problemas con las definiciones relativas a la ambigüedad léxica. En la mayoría de los casos se proporcionan definiciones excesivamente tajantes, como se recoge en la figura 3. Estas definiciones tan poco flexibles (aunque correctas), harán que sea complicada su matización en cursos superiores.

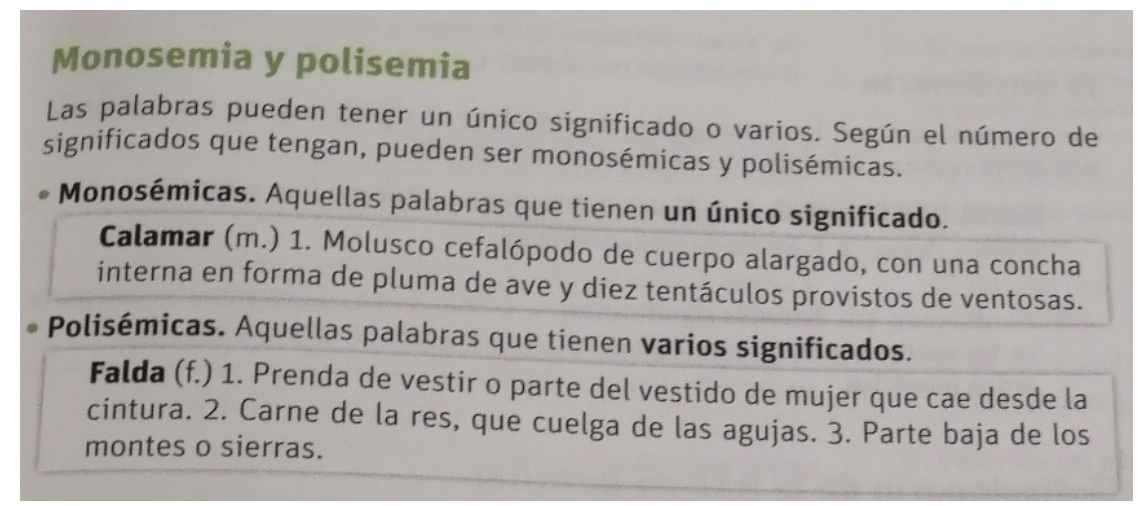

Figura 3. Fuente: extraída de SM1E

En la figura 3 se hace evidente la confusión entre los términos polisemia y ambigüedad. Aunque es cierto que las palabras polisémicas son aquellas que tienen varios significados, presentar así el fenómeno hace que el concepto de la homonimia sea difícil de integrar en la red de conocimientos de los alumnos. Sería más beneficioso presentar en este curso las definiciones de monosemia y ambigüedad y dejar para más adelante la oposición polisemia-homonimia.

Otro aspecto negativo presente en el manual de la figura 3 (así como en otros manuales) es la mala selección de ejemplos. La definición de la monosemia se ilustra con la palabra calamar. Sin embargo, al pensar en la palabra calamar recuperamos varios significados: el molusco, pero también un tipo de comida. Es cierto que ambos significados están estrechamente relacionados, pero eso no implica que la palabra sea monosémica. Lo que va a ocurrir es que los alumnos contrastarán la información del libro (calamar es una palabra con un único significado) y su propio conoci-

8 Este proceso se ha encontrado también en español, como demuestran los datos experimentales de López-Cortés (2019). 
miento como hablantes (calamar tiene varios significados) y, al ver que no coinciden, se producirá un desligamiento total entre lo presentado en clase y su instrumento de comunicación. Se conseguirá, por tanto, que los alumnos consideren la lengua como algo ajeno a ellos mismos.

En algunos casos sí que encontramos una presentación conjunta de la polisemia y de la homonimia, como se refleja en la figura 4. Sin embargo, al leer las definiciones, se puede ver que no se presenta ni una definición sincrónica ni diacrónica de los tipos de ambigüedad. Es más, ambas definiciones vienen a decir lo mismo: son palabras que tienen varios significados diferentes. La definición de la homonimia pretende hacer hincapié en la vertiente ortográfica del fenómeno (homofonía y homografía) pero lo hace de tal manera ("se pronuncian igual") que resulta problemático (¿acaso las palabras polisémicas no se pronuncian igual?).

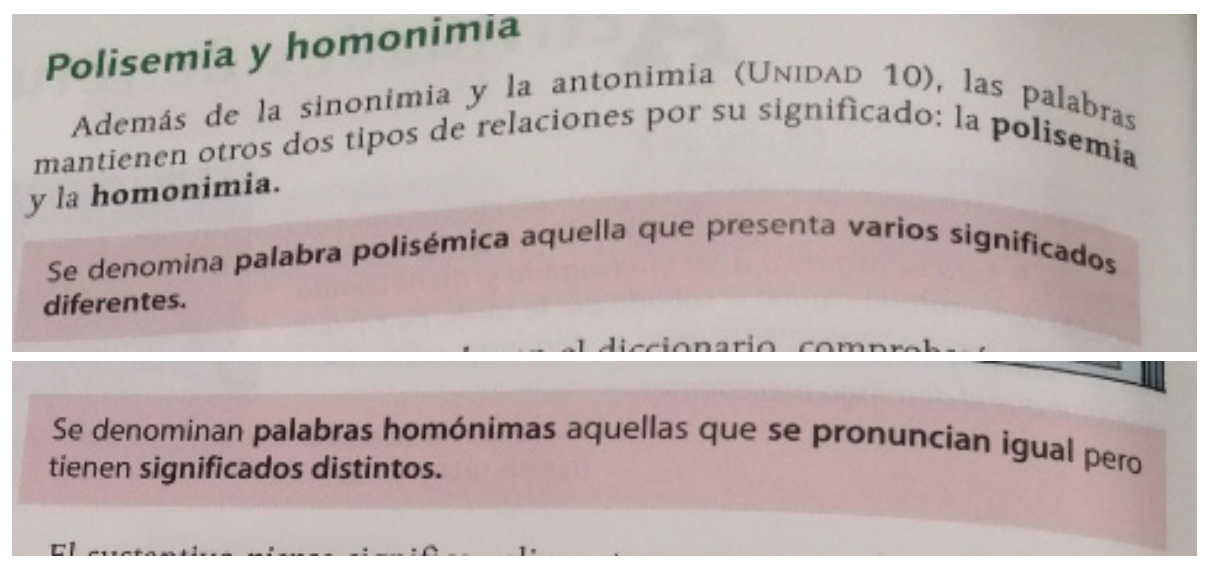

Figura 4. Fuente: extraída de SANT3E

Por último, es necesario mencionar dos aspectos relativos a la organización y estructuración de los apartados en los que se presenta la ambigüedad léxica. En primer lugar, consideramos necesario establecer una distinción clara entre ambigüedad léxica y otros fenómenos semánticos como la sinonimia, la antonimia o los campos semánticos. El estatus teórico de las relaciones semánticas y de la ambigüedad léxica no es el mismo. Como proponen Horno-Chéliz y López-Cortés $(2020,45)$, "los manuales que vayan a hablar de semántica léxica deberán presentar, al menos, dos apartados diferentes, tal que en uno de ellos se hable de cómo significan las palabras (y reflexionen sobre la ambigüedad) y, en otro, se hable de las relaciones que se establecen entre las palabras en virtud de su significado".

En segundo lugar, se hace evidente que en muchos casos se desaprovechan momentos ideales para poner en relación otros conceptos de la asignatura con la ambigüedad léxica. Por ejemplo, en la figura 5, se habla de metáfora como un mecanismo de cambio semántico y se utiliza como ejemplo la palabra boca, de naturaleza polisémica. Esta sería una buena oportunidad para poner en relación los mecanismos metafóricos con la polisemia y la extensión de significado.

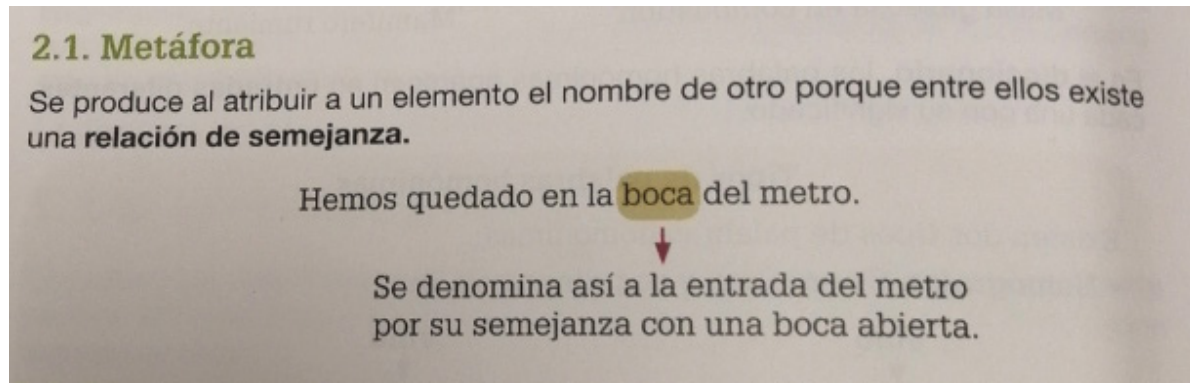

Figura 5. Fuente: extraída de SANT3E

El mismo proceso se podría hacer con la metonimia, que hace que palabras como plato sean polisémicas y puedan significar el objeto o la comida que se sirve en él, o con la elipsis, que hace que la palabra puro mantenga un significado como adjetivo y otro como sustantivo (ejemplos extraídos de Escandell, 2008). Estos ejemplos son una muestra más de que los contenidos de la clase de lengua están mucho más interrelacionados de lo que se da a entender a los alumnos.

\subsection{Reflexiones metodológicas}

En este apartado se van a proponer reflexiones metodológicas que permitan a los profesores enriquecer el material del que disponen para tratar el tema de la ambigüedad léxica de una manera más adecuada y enriquecedora. El objetivo 
final es que los alumnos vean la lengua "como un terreno para el descubrimiento y la experimentación" (Bosque y Gallego, 2018, p. 148).

En general, la mayoría de los ejercicios propuestos en los manuales disponibles son acertados y se pueden aprovechar puesto que proporcionan al profesorado material que, de otra manera, supondría un gran trabajo crear. Existen, sin embargo, algún tipo de ejercicio que consideramos poco útil en relación con la reflexión metalingüística, como son, por ejemplo, los que piden al alumnado que elaboren acepciones de palabras ambiguas o que consulten significados directamente en el diccionario. De cualquier manera, estos son los menos, por lo que queremos mostrar aquí ejercicios que pueden resultar todavía más provechosos si se les añade algún ingrediente extra.

El ejercicio de la figura 6 es un buen ejemplo de lo que se suele hacer para trabajar la oposición homonimiapolisemia. En él se pide a los alumnos que digan cuál es el significado de las palabras subrayadas: como están introducidas en un contexto, se produce una desambiguación hacia un significado concreto. Después, se pide que se clasifiquen como polisémicas u homónimas.

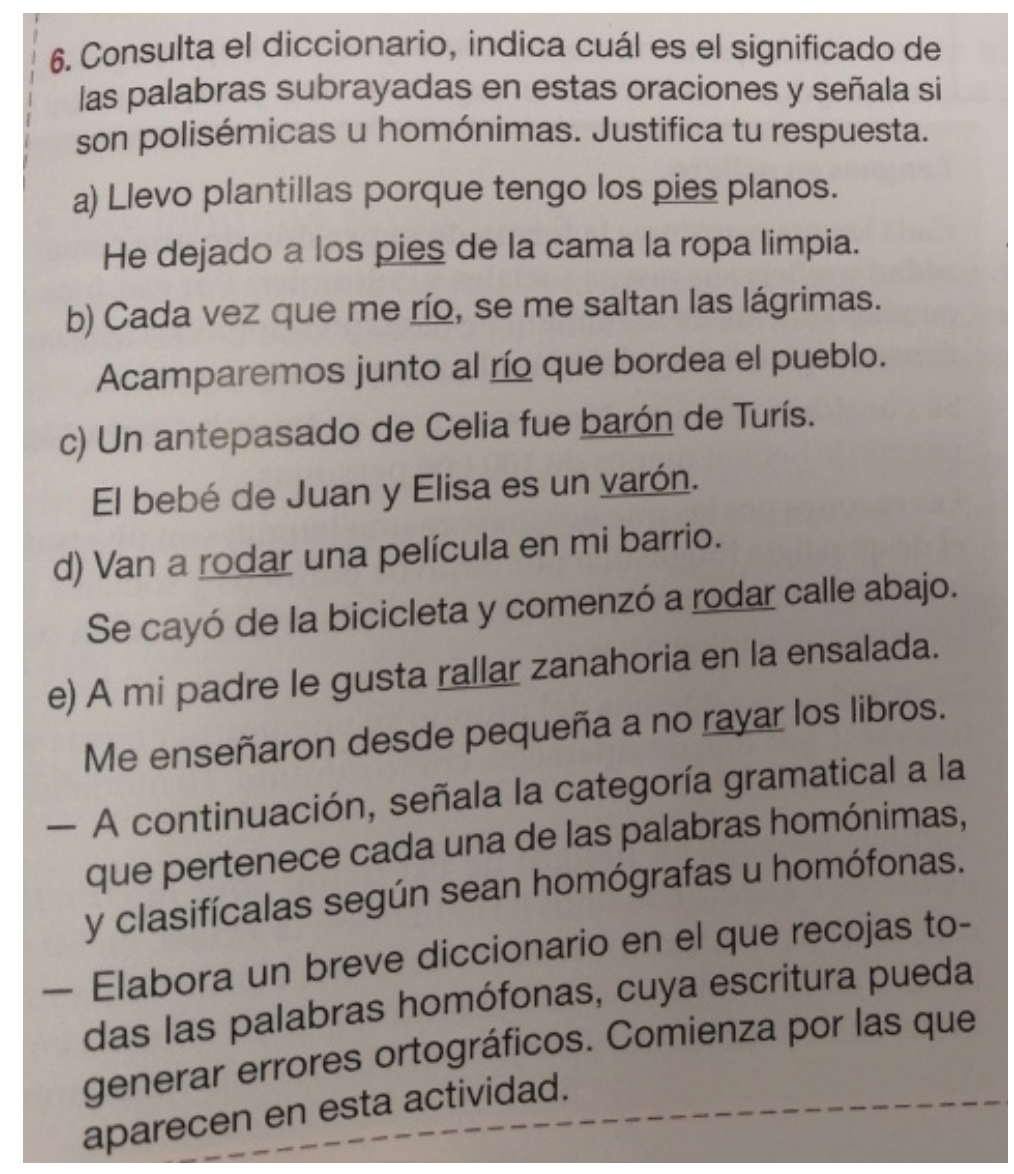

Figura 6. Fuente: extraída de SANT3E

Este ejercicio podemos replantearlo y presentarlo siguiendo los pasos de (2).

2) a. Piensa en las palabras pies, río y rodar. ¿Son monosémicas o ambiguas?

b. Lee estos pares de oraciones y explica qué significado de la palabra se utiliza en cada caso.

c. ¿Crees que las palabras pies, río y rodar son polisémicas o homónimas atendiendo a la relación entre significados?

d. Si crees que alguna es polisémica ¿qué relación encuentras entre sus significados?

e. Busca las palabras en el diccionario. ¿Coincide la información con lo que tú has respondido? ¿Hay algún significado extra que no conocías? En tu opinión, ¿están relacionados los significados del diccionario o no encuentras ninguna relación?

De esta manera se parte del conocimiento de los alumnos como hablantes del español y se hace hincapié en un hecho esencial: la lengua es un sistema interno, que nos pertenece y en el que ya somos expertos. La clase de lengua tiene que despertar la curiosidad por ese instrumento, utilizando el conocimiento (en este caso semántico) que ya tenemos atesorado en nuestra cabeza; aunque luego contrastemos la información con el diccionario y la maticemos. Siguiendo estos pasos los alumnos están siendo partícipes de la reflexión semántica. 
Otro tipo de ejercicio muy provechoso es el de los pares mínimos (Bosque y Gallego, 2016), los cuales consisten en presentar parejas de oraciones con cambios mínimos y cuyo objetivo es fomentar la reflexión lingüística. Un ejemplo de par mínimo relacionado con la ambigüedad léxica podría ser el recogido en (3), donde la agramaticalidad viene dada por el doble significado de la palabra pies y su combinatoria con otros elementos léxicos. Así se permite la doble combinación de $3 a$ ('lugar') pero no la de $3 b$ ('parte del cuerpo'):

3) a. Caí a los pies de María/Caí a los pies de la cama

b. A María le duelen los pies/*A la cama le duelen los pies

Otra aproximación muy conveniente al tema de la ambigüedad léxica es la que parte del humor (para un repaso sobre los mecanismos humorísticos en relación con la ambigüedad, véase Simarro, 2017). Algunos manuales dan cuenta de esta relación entre ambigüedad-humor, como se muestra en la figura 7. Normalmente, una palabra ambigua se desambigua por el contexto y por los mecanismos comunicativos, puesto que el emisor sabe qué significado quiere utilizar y el receptor puede desambiguarlo y seleccionar el correcto. Sin embargo, se puede jugar con la ambigüedad para generar situaciones cómicas donde la clave es la doble interpretación de las palabras ambiguas (como sucede en la figura 7 con problemas).

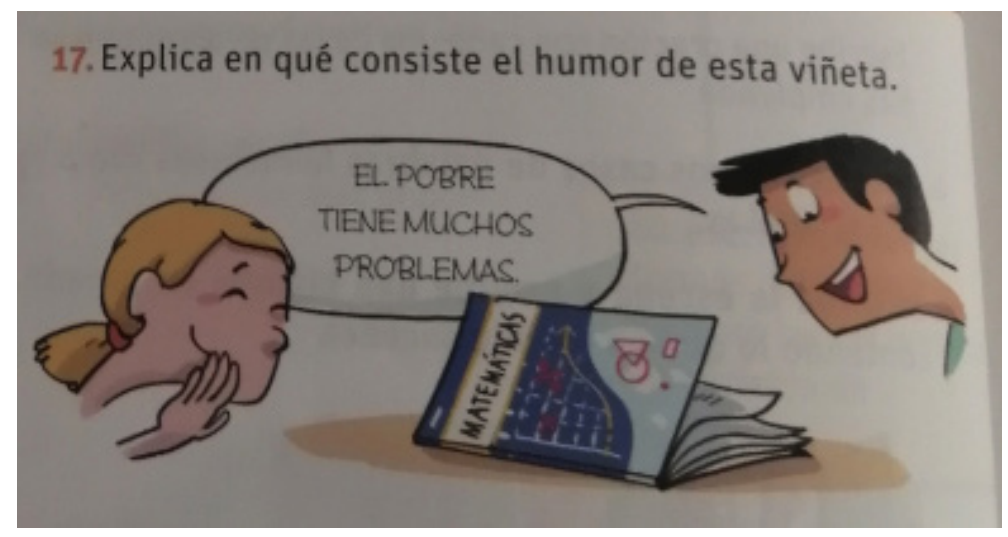

Figura 7. Fuente: extraída de SM4E

Tratar la ambigüedad léxica desde el humor, en Secundaria, puede ser muy productivo, puesto que introduce un componente de motivación. Una buena fuente de recursos para el estudio de la ambigüedad desde el humor es la plataforma de Twitter y, en concreto, basar la búsqueda en la etiqueta \#twitterparalinguistas. Bajo esta etiqueta se recogen diferentes tweets interesantes desde un punto de vista lingüístico y uno de los hilos más activos es el relacionado con la ambigüedad. De este recurso se pueden extraer ejemplos para trabajar en el aula, válidos para diferentes niveles.

Para acabar, proponemos un ejercicio partiendo de esta aproximación humorística. Podemos pedirles a nuestros alumnos que piensen en la palabra luna y preguntarles si creen que es monosémica o ambigua. Lo más probable es que respondan que es monosémica, puesto que luna tiene un significado muy prominente y común ('satélite'), que será, por tanto, el más accesible para ellos. A continuación, se les puede mostrar el tweet de la figura 8 :

\section{Y. Yami @Yamiroguay.Aug 5, 2015 \\ -Guapa, te regalo la luna. \\ -Gracias, pero me la cubre el seguro.}

Figura 8. Fuente: tweet de @Yamiroguay, extraído de la etiqueta \#twitterparalinguistas

La pregunta que habría que hacer entonces es: ¿encaja el significado de luna con el que habías pensado con este tweet? Los estudiantes verán entonces que el juego de palabras viene dado porque la palabra luna tiene otro significado posible. A partir de aquí, se pueden trabajar varios asuntos (ampliar el vocabulario utilizando el diccionario, clasificar la unidad como polisémica u homónima, en cursos superiores tratar de explicar el proceso de extensión semántica). Así, se están haciendo explícitas las diferencias existentes entre el significado que nosotros almacenamos como hablantes y la información que recogen los diccionarios, que no tienen por qué ser equivalentes. Esto hace casi palpable el hecho de que los alumnos tienen información lingüística valiosa en su cabeza y que ellos son, por tanto, los protagonistas innegables de la asignatura de Lengua. 


\section{SINONIMIA}

\subsection{Repaso teórico}

La sinonimia es definida por el Diccionario de la Lengua Española como una "relación de igualad que hay entre el significado de dos o más palabras o enunciados". Esta definición general considera, por tanto, que dos palabras mantienen una relación semántica sinonímica cuando comparten el mismo contenido descriptivo. En este sentido, dos sustantivos como oliva y aceituna remiten a la misma realidad descriptiva, 'el fruto del olivo', y, por consiguiente, pueden ser interpretadas como sinónimos.

Esta definición que, en un primer momento, puede resultar intuitivamente sencilla, presenta controversia entre los estudiosos de la materia. En la actualidad, se debate todavía si es posible hablar de este concepto como una relación léxica con relevancia cognitiva o como un constructo teórico sin fundamentación empírica. Como consecuencia nos encontramos con toda una serie de posturas aparentemente irreconciliables. En este punto, lo que se hace es, por un lado, demostrar por qué no puede existir en las lenguas eso que se viene llamando sinonimia (Bréal, 1924; Croft y Cruse, 2004; Trujillo, 1976) y, por otro lado, mostrar lo contrario, que efectivamente existe (Gutiérrez Ordoñez, 1989; López García, 1990).

Por una parte, aquellos que intentan defender la existencia de la sinonimia consideran que los dos términos tienen que compartir el mismo contenido semántico y que, para que esta definición se cumpla, tienen que darse las premisas recogidas en (4):

4) a. Las proposiciones tienen que compartir el mismo valor de verdad.

b. Las proposiciones tienen que compartir los mismos efectos comunicativos.

c. Los términos tienen posibilidad de ser intercambiados libremente en cualquier contexto.

Estos tres criterios pueden parecer fáciles de cumplir si se sigue la definición; pero, no es así. Si tomamos de los ejemplos de Escandell (2008) dos verbos como descender y bajar, considerados sinónimos, nos daremos cuenta de que a veces sí que cumplen los tres requisitos (5a y $5 \mathrm{~b}$ ), pero que otras veces no es así (5c), en particular, el relativo a 4c:

5) a. Desciende las escaleras/Baja las escaleras

b. La bajada de la Bolsa/El descenso de la Bolsa

c. El hombre desciende del mono/*El hombre baja del mono

Por esta razón, Trujillo (1976) ha señalado que la sinonimia, como relación semántica, no es posible concebirla de manera rígida. Para este autor, lo único que existe son palabras que en algunos contextos se usan sinonímicamente: es decir, palabras que denotan lo mismo aunque no compartan totalmente el mismo contenido semántico porque añaden información connotativa.

Pese a que Gutiérrez Ordóñez (1989) enumera grupos de palabras que cumplen con las tres premisas, por la dificultad percibida en encontrar términos que aúnen siempre los criterios establecidos, se ha negado la posibilidad de que exista el fenómeno semántico de la sinonimia (Bréal, 1924; Croft y Cruse, 2004). Sentadas estas premisas no resulta extraño que la lingüística posterior estableciera como un axioma indiscutible que no puede existir una sinonimia «auténtica» (González, 1989). Hoy en día, lo más frecuente, en este sentido, es intentar matizar esta postura haciéndola más flexible.

Esta aproximación mucho más laxa considera, pues, que la relación de sinonimia consiste en que varios significantes puedan ser asociados a un mismo concepto, al margen de toda actualización concreta y con un grado de abstracción acorde con el nivel en el que nos situamos (González, 1989). En la medida en que estos términos cubren una misma parcela conceptual y se configuran como posibilidades de designación, el hablante tendrá que realizar un proceso de selección y optar por uno de ellos en cada acto lingüístico concreto. Por ejemplo, el término borrachera comparte con otros términos (como intoxicación etílica, cogorza o pedal) la capacidad de denotar al mismo contenido semántico ('un trastorno temporal a causa del consumo excesivo de alcohol'). Sin embargo, situacionalmente hablando, sabemos qué términos puede utilizar un médico en su informe (intoxicación etílica) y cuales no (trompa, cogorza o pedal). Esto pone de manifiesto la complejidad de la significación de las palabras y cómo la sinonimia se relaciona estrechamente con los conceptos de intensión y extensión del significado.

En este estado de cosas, lo interesante de este debate no es decidir qué postura tomamos, sino reflexionar y tratar de explicar empíricamente cuál es la más acertada. En este sentido, es igualmente necesario llevar estas discrepancias al aula para que los alumnos aprendan a ser críticos y a formar sus propias conclusiones, capacidades que debemos desarrollar en los estudiantes. Esta es una oportunidad única para que entiendan el fenómeno con mayor propiedad, se pregunten por la naturaleza del concepto y lo relacionen con conceptos previos como el significado connotativodenotativo o las variedades diatópicas, diastráticas y diafásicas.

\subsection{Repaso de los materiales didácticos}

En los manuales revisados para este trabajo se han encontrado de manera recurrente problemas con las definiciones del fenómeno, puesto que se proporcionan descripciones excesivamente simples y tajantes que no dan cuenta de la complejidad, como ocurre en el manual de la figura 9. 


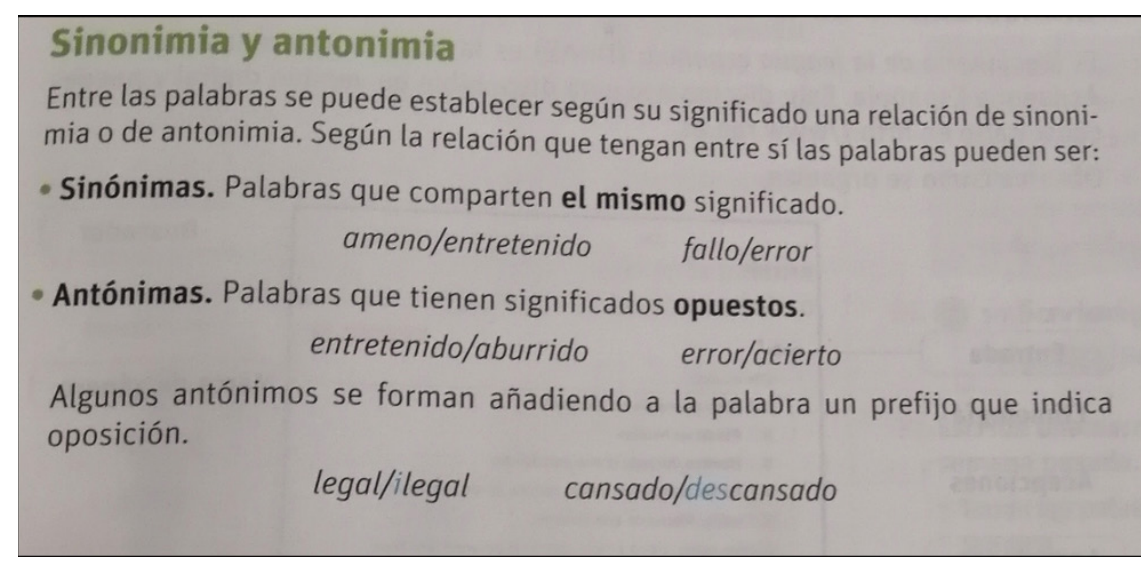

Figura 9. Fuente: extraída de SM1E

En la figura 9 se define la sinonimia como una relación entre dos palabras que comparten el mismo significado. Esta descripción del fenómeno lo presenta como una vinculación sencilla de cumplir y, además, consistente. Sin embargo, nuestros alumnos pueden ser conscientes de la complejidad de esta relación fijándose simplemente en el ejemplo ofrecido. Como hablantes sabemos que fallo y error no comparten siempre el mismo significado. Así, el par de oraciones de 6 a transmite el mismo significado, mientras que el de $6 \mathrm{~b}$ no:

6) a. He cometido muchos errores/fallos en este examen

b. El fallo/error de la sentencia fue nombrar culpable al acusado

En otro orden de cosas, no se considera útil presentar la sinonimia seguida de otro fenómeno lingüístico como la antonimia puesto que las relaciones que establecen no son análogas. Por una parte, la sinonimia establece una relación de términos basada en una misma realidad o referente denotado. Sin embargo, la antonimia relaciona dos términos distintos que, a su vez, remiten a dos representaciones distintas que, conceptualmente, se interpretan como opuestas.

Esta presentación conjunta de ambas relaciones semánticas se repite en los cuatro manuales de Secundaria que hemos consultado en este trabajo (SM1E, SM2E, SM3E y SM4E). Así mismo, se mantiene el gusto por presentar los fenómenos con definiciones simples y poco aclarativas, como se observa en la figura 10 extraída de un manual de $4 .^{\circ}$ de la ESO.

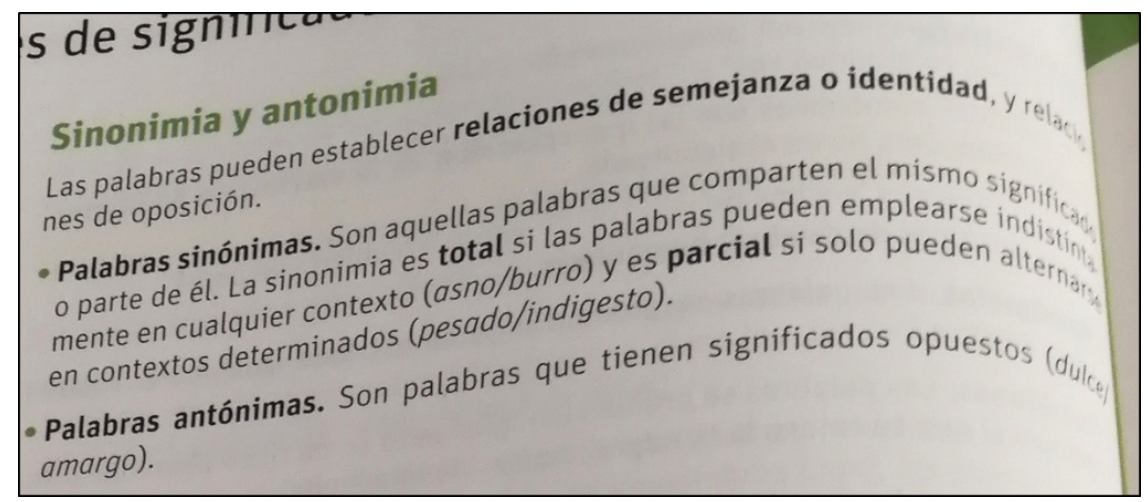

Figura 10. Fuente: extraída de SM4E

En la figura 10 se establece una disyuntiva que no facilita la diferenciación de este fenómeno con respecto a otros. En esta definición, se señala que las palabras sinonímicas son aquellas que "comparten el mismo significado o parte de él". El sintagma introducido por la conjunción disyuntiva "o" presenta este fenómeno muy próximo a las relaciones entre hipónimos e hiperónimos y, por tanto, siguiendo dicha definición, los estudiantes podrían considerar como sinónimos moto y coche, puesto que ambos, comparten parte de su significado 'automóvil'. A todo ello se suma que el ejemplo de asno/burro no cumple, de nuevo, con la explicación proporcionada a colación de la sinonimia total. De este modo, nuestros alumnos, como hablantes de español, saben que no es verdad que ambos términos aparezcan siempre en el mismo contexto lingüístico, como se evidencia en (7):

7) a. El otro día me compré un burro de ropa en IKEA, estaba a mitad de precio.

b. El otro día me compré un *asno de ropa en IKEA, estaba a mitad de precio. 
En suma, lo ideal es tratar esta relación semántica de manera independiente, alejada del fenómeno de la antonimia, puesto que el alumnado puede considerarlas relaciones contrapuestas, cuando en realidad son relaciones de distinto nivel de análisis. Sin embargo, sí que es útil relacionar la sinonimia con otras cuestiones como el significado denotativo y connotativo. Además, se recomienda, desde cursos iniciales, presentar la tipología que opone la sinonimia absoluta a la sinonimia parcial para que los ejemplos se ajusten a la teoría, evitando así que las explicaciones no parezcan estar fundamentadas empíricamente. De esta manera, desde $1 .^{\circ}$ de la ESO, podemos hablar de dos tipos de sinonimia, una mucho más rígida y otra más flexible. Y a partir de un ejemplo sencillo podemos explicarles que, pese a la operatividad de esta relación para organizar las palabras en nuestro lexicón mental, no es rentable que todas las palabras cuenten con un sinónimo absoluto porque esto sería poco económico para los procesos de adquisición.

\subsection{Reflexiones metodológicas}

En este apartado se van a proponer unas reflexiones metodológicas que permitan a los profesores enriquecer el material del que disponen en los libros de texto para tratar el fenómeno de la sinonimia de una manera más significativa.

En primer lugar, se aconseja evitar ejercicios como los que aparecen en la figura 11. Esta actividad no hace reflexionar al alumno sobre lo que ha aprendido sobre el fenómeno. Únicamente consigue ratificar que es hablante nativo de su lengua materna y que sabe relacionar intuitivamente aquellas palabras relacionadas sinonímicamente de aquellas que no lo están. Para los estudiantes es relativamente sencillo saber que tranquilo es sinónimo de sosegado y que, por su parte, contento lo es de alegre; pero no se les permite pensar críticamente por qué utilizamos en nuestro día a día más habitualmente la palabra tranquilo para decir el gato de Vicente es tranquilo, en lugar de decir el gato de Vicente es sosegado.

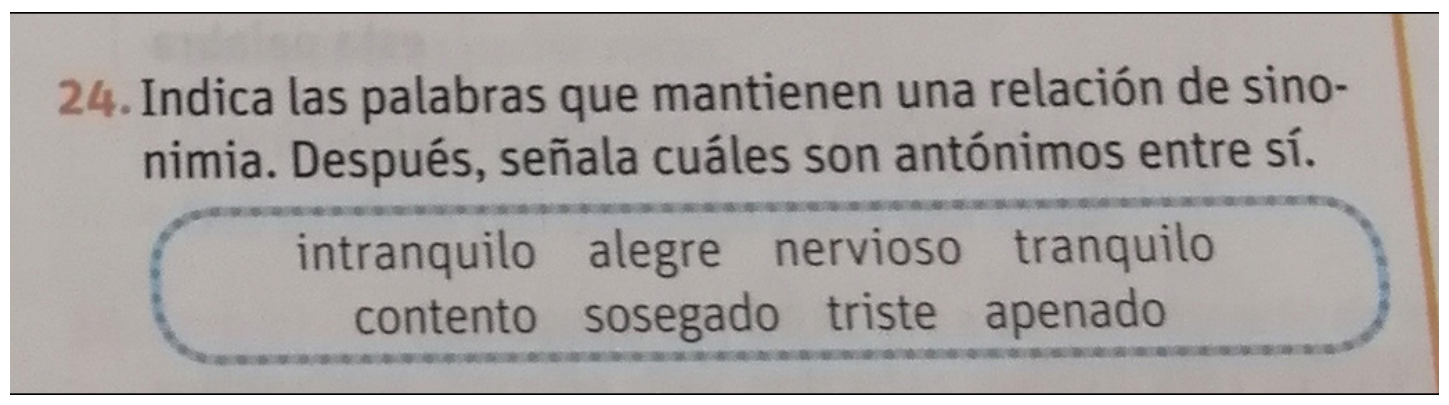

Figura 11. Fuente: extraída de SM1E

Una opción es sustuir ejercicios como los de la figura 11 por otros como los de la figura 12. En esta actividad se separa, por un lado, la sinonimia y la antonimia; y por otro lado, se propone la búsqueda de términos sinonímicos a partir del contexto lingüístico. De esta forma, el alumnado ve que un mismo término, como puede ser bueno/a, mantendrá una relación de sinonimia con un término y no con otro dependiendo del enunciado en el que esté ubicado. En este punto, es tarea del docente preguntarles a los alumnos, después de que completen el ejercicio, qué han aprendido de la naturaleza semántica de esta relación lingüística.

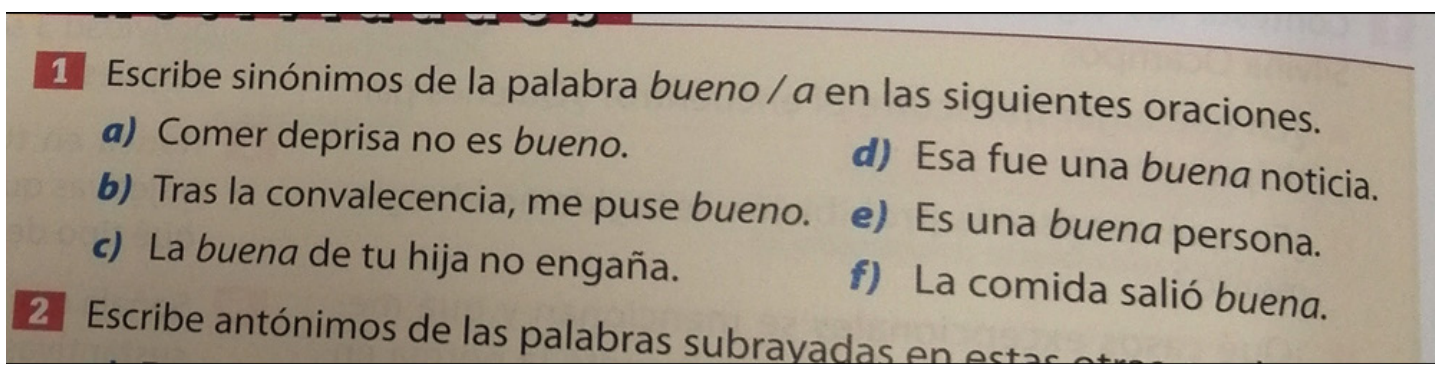

Figura 12. Fuente: extraído de SM3E

Para acabar, se propone un ejercicio que parte del uso de diccionarios de sinónimos, obras de consulta muchas veces olvidadas en la clase de Secundaria (Maldonado, 1998). El interés de esta actividad reside en la creatividad que promueve en nuestro alumnado. A partir de ella, podemos explicar para qué sirve este fenómeno lingüístico en nuestra capacidad del lenguaje. Con él, al mismo tiempo, podremos despertar el interés por la investigación psicolingüística. ¿De qué manera? La explicación es simple. Les pedimos a los alumnos que creen una nube de palabras de términos relacionados entre sí sinonímicamente. En ella tienen que justificar y argumentar cómo cada una de las 
palabras podría estar relacionada con el resto en nuestro lexicón mental, esto es, en nuestro cerebro. Para ello, tienen que partir de un significado y buscar todas las palabras que pueden remitir a este mismo.

En la figura 13 se ofrece un ejemplo reducido de lo que podría ser el resultado final de esta actividad. En esta ocasión se ha partido del término guapo. A partir de él, los alumnos tendrían que proponer una lista de términos que podrían considerarse sinónimos de esta palabra sin atender, en un primer momento, al contexto de uso. Lo más probable es que surgieran, en primer lugar, los más frecuentes, como bello, agraciado, atractivo o apuesto. Posteriormente, se les pediría que buscaran en el diccionario de sinónimos algunos otros significantes que pudieran estar relacionados. En esta búsqueda, podrían aprender nuevos términos como apolíneo o adonis, menos utilizados por la población juvenil y cuyo contexto de uso no pertenece al registro informal. Y llegados a este punto, se les ofrecería términos marcados diatópicamente, por ser muy frecuentes en otras variedades del español, como el adjetivo lindo, muy usado en el español de Argentina.

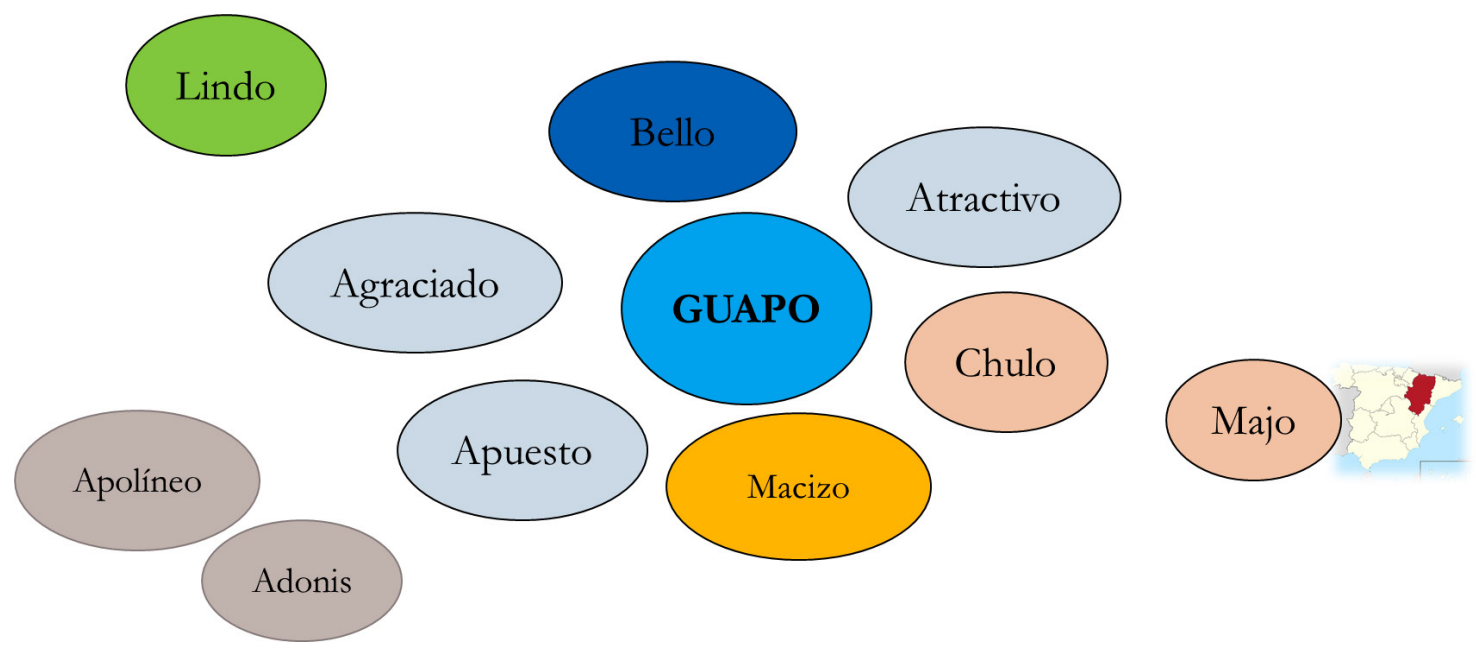

Figura 13. Nube de palabras.

Por último, se atendería al contexto de uso. En este punto, los alumnos tendrían que establecer cuándo se usan cada uno de los términos, ofreciendo un ejemplo con cada uno de ellos. En último lugar, tendrían que crear una posible red, considerando toda esta complejidad y utilizando para reflejarla diferentes colores, distancias más o menos próximas, etc... Esta red podría acompañarse de una leyenda y una breve explicación. Así, verían que chulo no es un sinónimo de guapo cuando se aplica a personas; pero sí cuando nos referimos a un coche. Y que el término majo se utiliza para describir a una persona atractiva en la variedad diatópica del español de Aragón, pero no es frecuente en otras.

En definitiva, con estas actividades conseguimos que los alumnos comprendan cómo funciona el lenguaje y, al mismo tiempo, amplíen su riqueza léxica, puesto que les hacemos conscientes mediante la introspección práctica de aspectos pragmáticos (variación diafásica) y de aspectos dialectales (variación diatópica). Y todo ello de una manera reflexiva y metalingüística.

\section{CONCLUSIONES}

En este trabajo se ha buscado reafirmar la importancia de la Semántica en el aula a partir de dos de los fenómenos lingüísticos que más se tratan en Secundaria: la ambigüedad léxica y la sinonimia. Con este objetivo, se han actualizado las bases teóricas de estas dos cuestiones en las que se ha hecho evidente la complejidad de estos dos fenómenos. Desde este punto de partida, se ha querido mostrar cómo aplicar estos avances para conseguir que el alumnado adquiera un espíritu crítico que le permita reflexionar sobre cuestiones lingüísticas.

En esta línea, se han revisado algunos materiales con los que los docentes trabajan en el aula para que, a partir de ellos, se puedan establecer actividades significativas que consigan que los estudiantes aprendan a reflexionar. Estos ejercicios parten de los materiales disponibles en los centros puesto que cuentan con ejemplos y recursos útiles que únicamente necesitan ser actualizados y explotados desde una perspectiva más activa y reflexiva, para conseguir el objetivo que se persigue en el área de Conocimiento de la Lengua del Currículo.

\section{BIBLIOGRAFÍA}

Ariño-Bizarro, Andrea y Natalia López-Cortés (2020). La semántica en el aula. En Psylex (org.). Zaragoza Lingüística a la Carta. Universidad de Zaragoza. Https://sites.google.com/view/zl-a-la-carta/zl-a-la-carta/la-gram\%C3\%A1ticaen-el-aula/la-sem\%C3\%A1ntica-en-el-aula 
Ausubel, David P. (1960). The use of advance organizers in the learning and retention of meaningful verbal material. Journal of Educational Psychology, 51, 267-272. Https://doi.org/10.1037/h0046669.

Bosque, Ignacio y Ángel J. Gallego (2016). La aplicación de la gramática en el aula. Recursos didácticos clásicos y modernos para la enseñanza de la gramática. RLA. Revista de Lingüistica Teórica y Aplicada, 54(2), 63-83. Https:// doi.org/10.4067/s0718-48832016000200004.

Bosque, Ignacio y Ángel J. Gallego (2018). La gramática en la enseñanza media. Competencias oficiales y competencias básicas. ReGrOC. Revista de Gramática orientada a Competencias, 1, 141-201. Https://doi.org/10.5565/rev/regroc.20.

Bréal, Michel (1924). Essai de sémantique. Science des significations. París: Slatkine Reprínts.

Croft, William y D. Alan Cruse (2004). Cognitive Linguistics. Cambridge: Cambridge University. Https://doi.org/10.1017/ cbo9780511803864.

Escandell, María Victoria (2008). Apuntes de Semántica Léxica. Madrid: UNED.

Gallego, Ángel J., Natalia López-Cortés, Andrea Ariño-Bizarro y Marta Herrando-Casas (en prensa). La arquitectura de la gramática. En Ángel J. Gallego y Edita Gutiérrez Rodríguez (eds.). La enseñanza de la gramática: teorías, metodologías y competencias. Madrid: Visor.

González Martínez, Juan Miguel (1989). La sinonimia. Problema metalingüístico. Anales de Filología Hispánica, 4, 193-210.

Gutiérrez Ordoñez, Salvador (1989). Introducción a la semántica funcional. Madrid: Síntesis.

Horno-Chéliz, María del Carmen y Natalia López-Cortés (2020). Homonimia y polisemia en la enseñanza no universitaria: revisión y propuesta didáctica. ReGrOC. Revista de Gramática orientada a Competencias, 3(1), 37-53. Https://doi. org/10.5565/rev/regroc. 26 .

Ibarretxe-Antuñano, Iraide, Andrea Ariño-bizarro y Natalia lópez-cortés (en prensa). Semántica. En Bárbara Marqueta, Natalia López-Cortés y Andrea Ariño-Bizarro (eds.). Avances de la Lingüistica y su aplicación didáctica. Madrid: Akal.

López, Helena (2016). La Semántica. En J. Gutiérrez Rexach (ed.). Enciclopedia de Lingüistica Hispánica 1 (pp. 284300). Londres: Rouledge. Https://doi.org/10.4324/9781315713441.

López-Cortés, Natalia (2019). La interpretación subjetiva de la ambigüedad léxica: una aplicación lexicográfica. LinRed: Lingüística en la Red, 17, 1-16. Https://doi.org/10.37536/linred.2020.xvii.3.

López García, Ángel (1990). Sinonimia intralingüística y sinonimia interlingüística. Actas del Primer Coloquio Internacional de Traductología (pp. 41-45). Valencia

Maldonado, Concepción (1998). El uso del diccionario en el aula. Barcelona: Arco Libros.

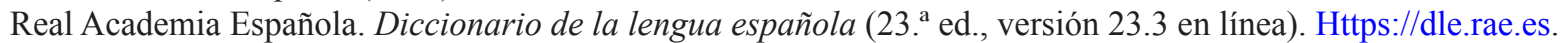

Real Decreto 1105/2014, de 28 de febrero, por el que se establece el currículo básico de la Educación Primaria. Boletín Oficial del Estado, 3 de enero de 2015. Https://www.boe.es/boe/dias/2015/01/03/pdfs/BOE-A-2015-37.pdf.

Saussure, Ferdinand de (1987, [1916]). Curso de Lingüistica General. Madrid: Alianza Editorial.

Simarro, María (2017). Humor verbal basado en la ambigüedad léxica y competencia léxico semántica. Pragmalingüistica, 25, 618-636. Https://doi.org/10.25267/pragmalinguistica.2017.i25.31.

Spencer, Andrew (1991). Morphological theory: An introduction to word structure in generative grammar. Oxford: Basil Blackwell.

Trujillo, Ramón (1976). Elementos de Semántica lingüistica. Madrid: Cátedra.

\section{Manuales consultados}

Lengua castellana y Literatura $1^{\circ}$ ESO (Serie Savia) (2015). Madrid: SM. Https://es.smsavia.com/proyecto/secundaria/ lengua [SM1E].

Lengua castellana y Literatura $3^{\circ}$ ESO (Serie Libro abierto) (2015). Madrid: Santillana. Https://santillana.es/lengua-castellana-y-literatura-libro-abierto-3-eso-2/ [SANT3E].

Lengua castellana y Literatura $2^{\circ}$ ESO (Serie Savia) (2016). Madrid: SM. Https://es.smsavia.com/proyecto/secundaria/ lengua [SM2E].

Lengua castellana y Literatura $3^{\circ}$ ESO (Serie Savia) (2016). Madrid: SM. Https://es.smsavia.com/proyecto/secundaria/ lengua [SM3E].

Lengua castellana y Literatura $4^{\circ}$ ESO (Serie Savia) (2016). Madrid: SM. Https://es.smsavia.com/proyecto/secundaria/ lengua [SM4E]. 